\title{
DEATH OF A MAN MANAGED FOR BACKACHE FOLLOWING A FALL FROM A HEIGHT
}

\author{
Kitulwatte I.D.G \\ Department of Forensic Medicine, Faculty of Medicine, University of Kelaniya, \\ Sri Lanka
}

\begin{abstract}
This case illustrates a death of a man who had fallen from a height and managed for fracture of spine who had ultimately died of an unexpected, under-attended pathology.

A 35-year-old previously healthy man had a fall from a height and was admitted to a surgical ward with backache. He was diagnosed to have a fracture of the $12^{\text {th }}$ thoracic and $1^{\text {st }}$ lumbar vertebrae. On the $14^{\text {th }}$ day after the fall he became confused but was not febrile. Condition worsened and he succumbed on the $15^{\text {th }}$ day. Examination of the x-ray spine revealed the "fracture" of the $12^{\text {th }}$ thoracic vertebra.
\end{abstract}

At autopsy a defect in the spine was detected with no associated hemorrhage. There was subcutaneous and muscle contusions of the right sacral area with no associated bony injuries. The kidneys were enlarged, congested, oedematous with multiple abscesses indicating acute pyelonephritis.

It may be concluded that other possibilities of back ache unrelated to trauma need to be considered in persons who fall from heights.

Key words:

Fall, Backache, Spine, Fracture, Pyelonephritis

All articles in Sri Lanka Journal of Forensic Medicine, Science \& Law are licensed under the terms of the licensed under a Creative Commons Attribution-Non Commercial 4.0 International License. 


\section{INTRODUCTION}

Congenital abnormalities mimicking fractures are rare. $^{1}$ Most of these abnormalities are asymptomatic and are a diagnostic challenge to the treating physician. Unfortunately, conventional radiological imaging may be unhelpful in differentiating congenital abnormalities such as platysopondyly from fractures. ${ }^{2}$

\section{CASE REPORT}

A 35-year-old previously healthy man had a fall from a height of 18 feet and was admitted to a surgical ward with backache. X-ray of the spine revealed a "wedge fracture" of the $12^{\text {th }}$ thoracic vertebra (Fig. $1,2)$.

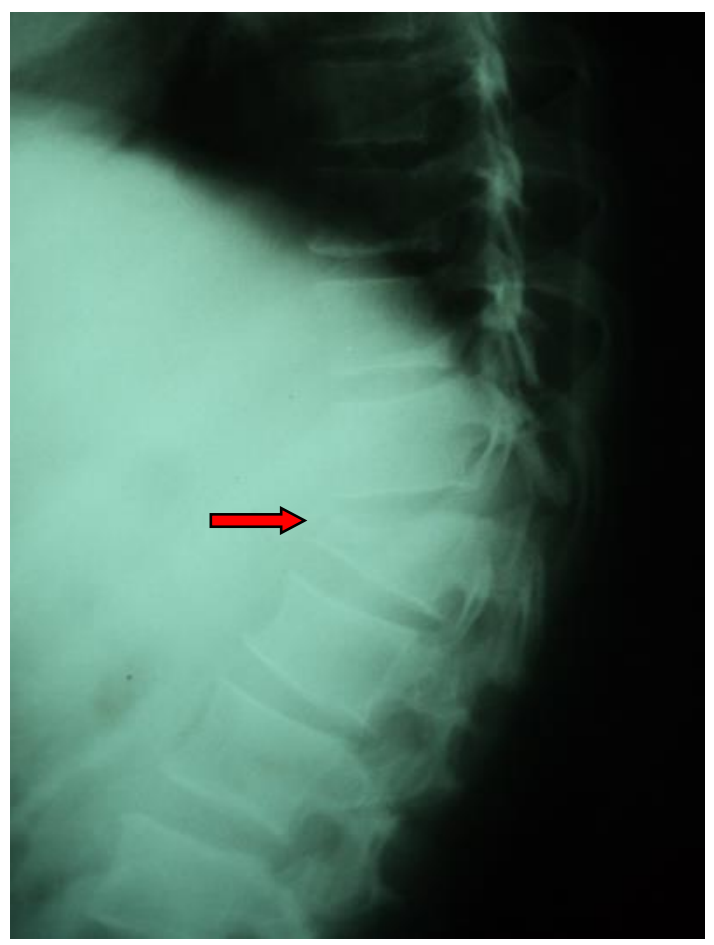

Fig. 1: Radiograph of the spine lateral view showing wedge indicated by arrow

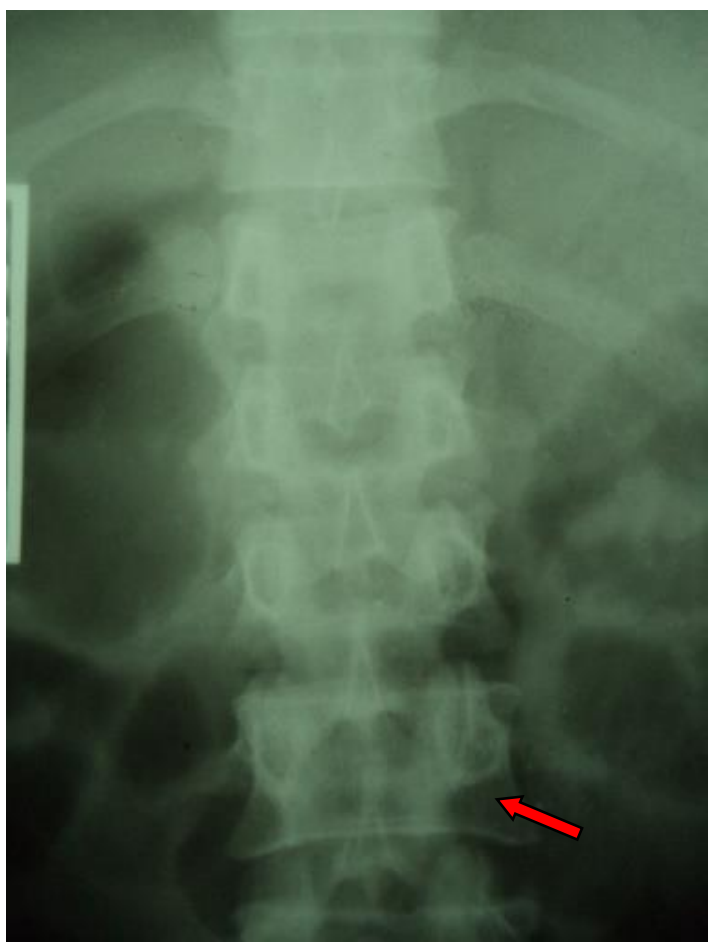

Fig. 2: X-ray spine AP view showing the bony defect with arrow

There was no record of any significant past medical history including urinary tract infections or pyelonephritis. There was no recorded fever. Thus, the management was mainly directed towards orthopedic care, specially, stabilization of spine following referral to an orthopedic surgeon. In spite of the management he continued to have backache. On the $14^{\text {th }}$ day after the fall he became confused, but was not febrile. The condition worsened and he succumbed on the $15^{\text {th }}$ day.

Since it was considered to be a death following accidental trauma, an inquest was ordered and the body was subjected to a medico legal autopsy under the authority of the Inquirer in to Sudden Deaths. The body was that of a well-nourished and welldeveloped man, 64" in height. There were no external injuries. There was an anterior wedge shaped defect in the spine with no associated hemorrhage. There was subcutaneous and muscle contusion of the right sacral area with no associated bony injuries (Fig. 3). 


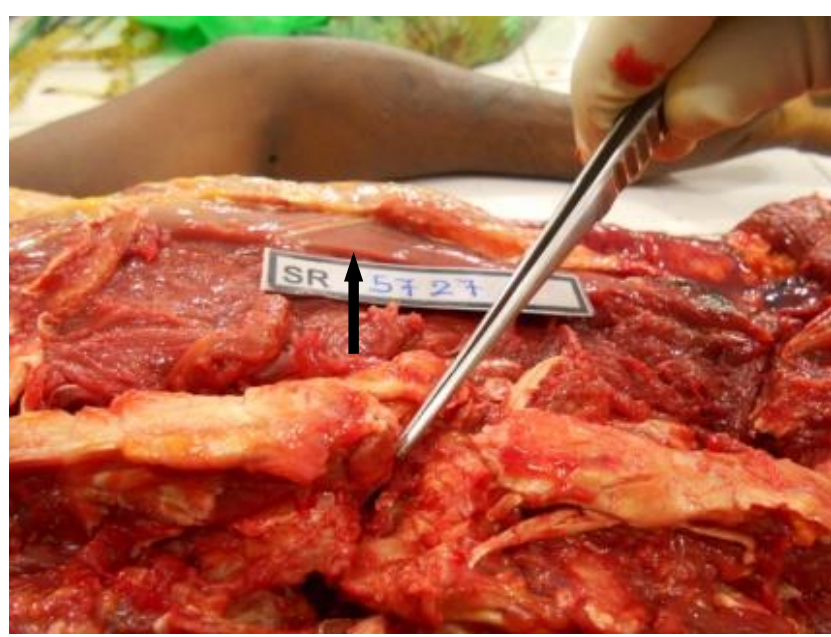

Fig. 3: Dissected spine showing the non haemorrhagic gap between $12^{\text {th }}$ Thoracic and $1^{\text {st }}$ lumbar vertebrae.

Arrow pointing toward the contusion over the sacrum.

The kidneys were enlarged, congested, oedematous with multiple abscesses.

(Fig. 4).

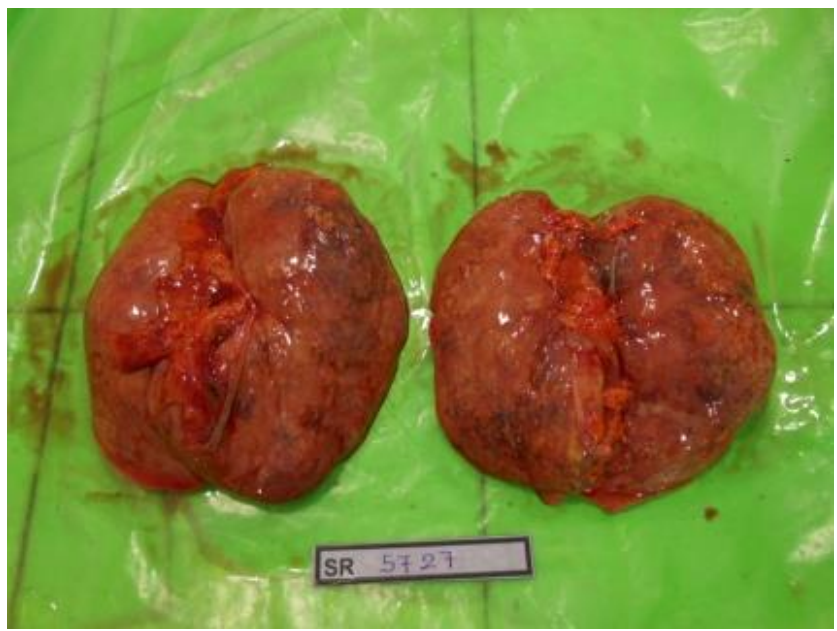

Fig. 4: Kidneys showing small white/pale abscesses on sub capsular surface.

Histology revealed acute on chronic pyelonephritis (Fig. 5). No other pathology was noted. The cause of death was concluded as pyelonephritis and the circumstance was natural.

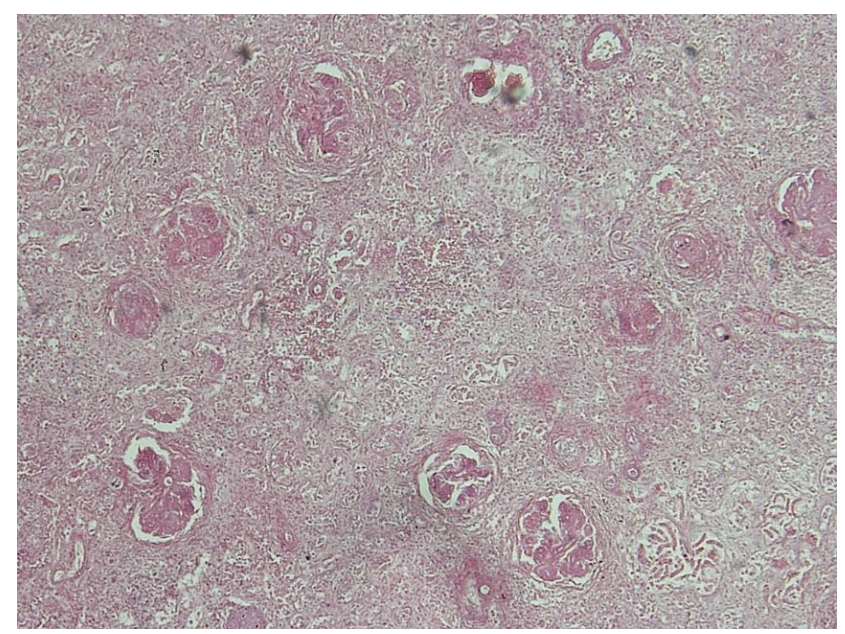

Fig. 5: Microscopy of the kidney with acute on chronic pyelonephritis.

\section{DISCUSSION}

There are four basic mechanisms of vertebral injuries: flexion, extension, shearing, and rotary movements. ${ }^{3,4}$ Lumber vertebral wedge fractures are known to occur in falls from height. ${ }^{5}$ Although back pain is often caused by injury and evidence of spinal trauma can easily be evaluated and is obvious, it is important to focus on other pathologies especially when the pain is not responding or worsening during the course of treatment. Attention should have been paid to exclude other potentially life threatening conditions.

Back pain may have many other underlying reasons. Aortic aneurysm, myocardial infarction, acute pancreatitis, duodenal ulcers, gynecological conditions, renal calculi, acute pyelonephritis and urinary tract infections are some of the serious conditions that can present with back pain needing urgent attention. ${ }^{6,7}$ This 35-yearold man was ultimately diagnosed to have pyelonephritis, which explains his worsening back pain irrespective of the management of trauma.

Pyelonephritis can cause lower back pain. The condition can be potentially lethal if unattended. Accurate and timely diagnosis and treatment can prevent serious complications. ${ }^{8}$ 
When there is a congenital abnormality of the spine mimicking a fracture in a man who presents with backache after falling from a height, other possibilities of backache could be missed.

Subtle difference in the symptoms in other causes of backache and confusion due to referred pain may mislead physicians. The clinical diagnosis of pyelonephritis is made on the history, physical examination, and urine analysis. Pyelonephritis may result in high fever and costovertebral angle tenderness with pain over the costovertebral angle on percussion. However, absence of fever and attribution of loin tenderness to trauma could be the reasons for misdiagnosis in this case.

Differential diagnosis between vertebral fractures and congenital or preexisting abnormalities can present a major clinical challenge, especially when the presentation is post traumatic. ${ }^{2}$ In this regard, a careful radiological evaluation is essential in order to make a correct diagnosis. However, patients may have conditions that mimic the imaging appearance of a lesion. ${ }^{9}$ Developmental anomalies of vertebrae may occur anywhere throughout the length of the spine and could affect any part of the vertebrae. ${ }^{10}$ This patient had a nonhemorrhagic wedge shaped defect involving the anterior part of the $12^{\text {th }}$ thoracic vertebral body, which is known as hemivertebrae. This defect can be asymptomatic especially when it involves the thoracic or lumbar spine. ${ }^{11,12}$ Congenital or developmental disorders of the spine are known to mimic fractures. ${ }^{13}$ Especially in falls from a height, anterior wedge fractures or compression fractures are commonly observed, which have a similar radiological appearance to this defect. ${ }^{14}$ However, at autopsy, absence of the haemorrhage confirmed that the condition was pre-existing.

In conclusion, when a potentially treatable condition is undetected till death, in a patient receiving medical care, the family, the public, as well as the judiciary, may raise the question of medical negligence. Successful conviction of medical negligence needs establishment of establishment of a doctorpatient relationship, harm to the patient, failure to provide the required standard of care under the circumstances by the doctor, and the harm being a result of such failure. In this case, the patient was admitted and managed for backache following trauma which establishes the doctor-patient relationship. He succumbed with worsening backache due to undetected and unattended pyelonephritis. Whether there is failure of any standard of care needs careful evaluation with application of Bolam as well as Bolitho's principles. ${ }^{15}$ If there is evidence of failure of standard of care leading to non-diagnosis of pyelonephritis, supported by a responsible body of similar professionals considering the presentation and the presence of the misleading vertebral defect, this case could be considered as a case of medical negligence.

\section{REFERENCES}

1. Cherian A, Jamkhandi D, George K, Bose A, Prasad J, Minz S. Prevalence of Congenital Anomalies in a Secondary Care Hospital in South India: A Cross-Sectional Study. Journal of tropical pediatrics. 2016 Apr 4;62(5):361-7. https://doi.org/10.1093/tropej/fmw019

2. Ganau M, Spinelli R, Tacconi L. Complex developmental abnormality of the atlas mimicking a Jefferson fracture: Diagnostic tips and tricks. Journal of emergencies, trauma, and shock. 2013 Jan;6(1):47. https://dx.doi.org/10.4103\%2F09742700.106325

3. Denis F, Burkus J. Shear Fracture Dislocations of the Thoracic and Lumbar Spine Associated with Forceful Hyperextension (Lumberjack Paraplegia). Spine. 1992 Feb;17(2):156-61. http://dx.doi.org/10.1097/00007632199202000-00007 
4. Jeanneret B, Ho P, Magerl F. Burst-Shear Flexion-Distraction Injuries of the Lumbar Spine. Journal of spinal disorders. 1993 Dec;6(6):473-81.

DOI: $10.1097 / 00002517-199306060-00002$

5. Cites B, Moorman C, Hardaker W. Spine injuries associated with falls from hunting tree stands. Journal of the Southern Orthopaedic Association. 1998;7(4):241-6.

6. Klineberg E, Mazanec D, Orr D, Demicco R, Bell G, McLain R. Masquerade: medical causes of back pain. Cleveland Clinic journal of medicine. 2007 Dec;74(12):90513. DOI: $10.3949 /$ ccjm. 74.12 .905

7. Der Sarkissian C. Causes of Back Pain. WebMD [Internet]. 2018 [cited 2018 May 17]. Available from:

https://www.webmd.com/back-pain/causesback-pain

8. Efstathiou SP, Pefanis AV, Tsioulos DI, Zacharos ID, Tsiakou AG, Mitromaras AG, Mastorantonakis SE, Kanavaki SN, Mountokalakis TD. Acute pyelonephritis in adults: prediction of mortality and failure of treatment. Archives of internal medicine. 2003 May 26;163(10):1206-12.

DOI:10.1001/archinte.163.10.1206

9. Tehranzadeh J, Rappard G, Anavim A. Spinal computed tomography and magnetic resonance imaging. In: Shirkhoda A, editor. Variants and Pitfalls in Body Imaging. Philadelphia: Williams and Wilkins; 1999.
10. Wynne-Davies R. Congenital vertebral anomalies: aetiology and relationship to spina bifida cystica. Journal of medical genetics. 1975 Sep 1;12(3):280-8.

http://dx.doi.org/10.1136/jmg.12.3.280

11. Löhnert C, K. Petridis A, Maslehaty H, Scholz M. Clinical Implications of the Rare Anomaly of a Cervical Hemivertebra over a Period of 30 Year. Journal of spine \& neurosurgery. 2013 Apr 01;02(02).

DOI:10.4172/2325-9701.1000111

12. Basu PS, Elsebaie H, Noordeen MH. Congenital spinal deformity: a comprehensive assessment at presentation. Spine. 2002 Oct 15;27(20):2255-9. DOI:10.1097/01.BRS.0000029425.58936.B A

13. James F. Griffith. Identifying osteoporotic vertebral fracture. Quantitative Imaging Medicine and Surgery 2015 Aug;5(4):592602

14. Brant, William E, helms, Clyde A. "Benign Compression Fracture". Fundamentals of Diagnostic Radiology. 3rd ed. Philadelphia: Lippincott Williams \& Wilkins; 2007.

15. Samanta A, Samanta J. Legal standard of care: a shift from the traditional Bolam test. Clinical Medicine. 2003 Sep 01;3(5):443-6. DOI: 10.7861/clinmedicine.3-5-443 